\title{
Efficiency of extractants to release As, Cd and Zn from main soil compartments
}

\author{
J. Száková*, P. Tlustoš, J. Balík, D. Pavlíková and M. Balíková \\ Department of Agrochemistry and Plant Nutrition, Czech University of Agriculture, \\ 16521 Prague 6, Suchdol, Czech Republic
}

\begin{abstract}
Various soil extraction methods were developed for the determination of total and/or plant-available concentrations of potentially toxic elements. In this experiment, four single extraction procedures (aqua regia, $\mathrm{HNO}_{3}$, acetic acid, DTPA) were tested for the determination of extractable contents of As, Cd and $\mathrm{Zn}$. 35 soils differing in their physicochemical properties and in total element contents were used in this experiment. Extractability of elements from soil samples varied following the individual elements and/or extraction agents used. The strong acids were not able to release the elements tightly bound into the silicate sample matrix. However, such techniques remain utilizable for the approximate determination of "pseudototal" element contents in soil, especially if soil samples are affected by anthropogenic contamination. The concentrations of As, Cd, and $\mathrm{Zn}$ determined in soil extracts by both mineral and organic acids covered in most cases the element portion representing more than one soil element fraction determined using SM\&T sequential extraction procedure. Solutions of acetic acid and DTPA were able to release a part of the element fraction bound in Fe/Mn oxides and organic matter of soil sample. Arsenic represents an exception because it is not released by DTPA.
\end{abstract}

Keywords. As - Cd - Zn - soil - extraction - aqua regia - nitric acid - acetic acid - DTPA.

\section{Introduction}

Potentially mobilizable element content of soil represents its portion which is tightly bound on the individual soil components (except the portion of elements incorporated into the silicate matrix of the soil), unavailable immediately for plants. Only the substantial changes in physicochemical properties of soil can lead to their higher mobility. For their extraction, strong acids are usually applied [1]. On the other hand, the soil extraction procedures using organic acids can partially release the elements bound in soil on surface of oxides and in organic matter [2-4].

The methods of sequential extraction of soils were developed in order to define more precisely the single fractions of elements in a soil. Sequential extraction usually necessitates from three to seven steps. Consequently, it is time consuming and requires skilled personal and an adequate analytical instrumentation. Nevertheless it gives the most precise information about fractionation and transformation of elements in a soil.

A large number of different methodological approaches arisen in last years because many analytical laboratories developed their own analytical methods defining individual fractions of given elements [5-7]. The basic method was developed by Tessier et al. [8], who performed fractionation of metals in samples of sediments into 5 fractions: (1) exchangeable fraction representing the most easily avail- able metals, (2) carbonate fraction, (3) Fe, Mn and Al oxides fraction, (4) organic matter fraction and (5) residual fraction, tightly bound on silicate matrix of samples.

The unification of methods for a simple and sequential extraction in European Community (EC) and later also the preparation of certified reference soil materials is one of the aims of Standards, Measurement and Testing (SM\&T) department of the EC [9].

The ability of soil extracting agents to release the plantavailable portion of elements was summarized in a previous paper [10]. In this work, the soil element fractions soluble in individual acid extractants are evaluated.

\section{Experimental Samples}

A set of 35 soil samples with different physicochemical properties covering the area of the Czech Republic was investigated. Some of the samples were also taken from the same location in different periods. The main characteristics of these soils are summarized in table I. Certified reference material RM 7003 Silty Clay Loam (Analytika, CZ) was used for quality assurance of analytical data. For the element portion extractable from this RM by a cold 2 mol. l $^{-1} \mathrm{HNO}_{3}$, the certified values are $1.30 \pm 0.19 \mathrm{mg} \mathrm{As}_{\mathrm{kg}}^{-1}$, $0.23 \pm 0.03 \mathrm{mg} \mathrm{Cd} . \mathrm{kg}^{-1}$ and $24.4 \pm 2.5 \mathrm{mg} \mathrm{Zn.kg}{ }^{-1}$. 


\section{Original articles}

Table I. The main characteristics of investigated soils.

\begin{tabular}{|c|c|c|c|c|c|c|c|}
\hline & $\begin{array}{l}p H \\
(\%)\end{array}$ & $\begin{array}{c}C_{o x} \\
\left(\mathrm{mval}_{\mathrm{kg}} \mathrm{kg}^{-1}\right)\end{array}$ & $\begin{array}{l}C E C \\
(\%)\end{array}$ & $\begin{array}{l}\text { clay particles } \\
\left(\mathrm{mg} \cdot \mathrm{kg}^{-1}\right)\end{array}$ & $\begin{array}{c}\text { total As } \\
\left(\mathrm{mg} \cdot \mathrm{kg}^{-1}\right)\end{array}$ & $\begin{array}{l}\text { total Cd } \\
\left(\mathrm{mg} \cdot \mathrm{kg}^{-1}\right)\end{array}$ & total Zn \\
\hline average & 6.2 & 2.26 & 187 & 20.8 & 43.3 & 2.06 & 119 \\
\hline median & 6.5 & 2.00 & 188 & 22.0 & 20.1 & 0.39 & 109 \\
\hline stand. deviation & 0.9 & 1.25 & 55 & 8.4 & 70.8 & 5.1 & 74 \\
\hline minimum & 3.6 & 0.70 & 89 & 10 & 4.4 & 0.11 & 35.8 \\
\hline maximum & 7.3 & 6.67 & 292 & 48 & 352 & 19.4 & 451 \\
\hline
\end{tabular}

$\mathrm{C}_{\mathrm{ox}}$ : content of oxidizable carbon

CEC: cation exchange capacity

\section{Extractions}

The extraction methods used are characterized as follows:

A. Extraction by aqua regia: $3 \mathrm{~g}$ of the sample were weighed into a $250 \mathrm{ml}$ reaction vessel, moisturized by a small amount of deionized water and mixed with $21 \mathrm{ml}$ of concentrated $\mathrm{HCl}$ and $7 \mathrm{ml}$ of concentrated $\mathrm{HNO}_{3}$. After a $16 \mathrm{~h}$ stay at $20^{\circ} \mathrm{C}$ the samples were heated for $2 \mathrm{~h}$ under reflux. After cooling down of the reaction mixture the reflux was rinsed by diluted $\mathrm{HNO}_{3}$, the sample filtered to $100 \mathrm{ml}$ volumetric flask, filled up the mark by diluted $\mathrm{HNO}_{3}$ and kept until measurement [11].

B. The next applied extraction procedures, described in details in a previous paper [12], may be summarized as follows:

1. extraction by 2 mol. $1^{-1}$ solution of $\mathrm{HNO}_{3}$ in ratio $1: 10(\mathrm{w} / \mathrm{v})$ at $20^{\circ} \mathrm{C}$;

2. extraction by 0.43 mol. $1^{-1}$ solution of $\mathrm{CH}_{3} \mathrm{COOH}$ in ratio $1: 40(\mathrm{w} / \mathrm{v})$;

3. extraction by $0.005 \mathrm{~mol}^{-1}$ solution of DTPA $\left(+0.1\right.$ mol. $1^{-1}$ trietanolamine $\left.+0.01 \mathrm{~mol}^{-1} \mathrm{CaCl}_{2}\right)$ in ratio $1: 2(\mathrm{w} / \mathrm{v})$.

Sequential analytical procedure: the soil samples were extracted according to the SM\&T EUR 14763 EN extraction scheme [5], modified by including a water soil extraction as the first step. The extraction scheme was then as follows: $0.5 \mathrm{~g}$ soil sample was weighed into centrifugation tubes and sequentially extracted by the following agents:

1. water soluble fraction by deionized water in ratio $1: 10$ $(\mathrm{w} / \mathrm{v})$;

2. exchangeable fraction by $0.11 \mathrm{~mol}^{-1} \mathrm{CH}_{3} \mathrm{COOH}$ in ratio $1: 40(\mathrm{w} / \mathrm{v})$;

3. fraction bound in $\mathrm{Mn} / \mathrm{Fe}$ oxides by $0.1 \mathrm{~mol} . \mathrm{1}^{-1}$ $\mathrm{NH}_{2} \mathrm{OH} . \mathrm{HCl}$ in ratio $1: 40(\mathrm{w} / \mathrm{v}), \mathrm{pH}=2$;

4. organically bound fraction by $8.8 \mathrm{~mol}^{\mathrm{l}^{-1}} \mathrm{H}_{2} \mathrm{O}_{2}$ in ratio $1: 40(\mathrm{w} / \mathrm{v})$ evaporated to dryness followed by $1 \mathrm{~mol} . \mathrm{l}^{-1}$ $\mathrm{CH}_{3} \mathrm{COONH}_{4}$ in ratio $1: 100(\mathrm{w} / \mathrm{v}), \mathrm{pH}=5$;

5. residual fraction calculated as the difference between total element concentration in the soil and the sum of the four described fractions.
The reaction mixture was centrifuged at $3000 \mathrm{rpm}$ (i.e. $460 \mathrm{xg}$ ) for 10 minutes at the end of each step and supernatants were kept at $6{ }^{\circ} \mathrm{C}$ before measurement. Blank extracts representing $5 \%$ of total number of extracts were prepared using the same batch of reagents and the same apparatus and analyzed in the same time and in the same way as soil extracts.

Total element concentrations in soils were determined separately in digests obtained by two-step decomposition as follows: 0.5 of sample was decomposed by dry ashing in a mixture of oxidizing gases $\left(\mathrm{O}_{2}+\mathrm{O}_{3}+\mathrm{NO}_{\mathrm{x}}\right)$ in an Apion Dry Mode Mineralizer (Tessek, CZ) at $400{ }^{\circ} \mathrm{C}$ for $10 \mathrm{~h}$; the ash was then decomposed in a mixture of $\mathrm{HNO}_{3}+\mathrm{HF}$, evaporated to dryness at $160{ }^{\circ} \mathrm{C}$ and dissolved in diluted aqua regia.

\section{Instrumentation and reagents}

For the centrifugation of the extracts, the Hettich Universal 30 RF (Germany) device was used. The element concentrations in soil extracts were determined by atomic absorption spectrometry as follows.

Arsenic was determined by a continual hydride generation technique using a Varian SpectrAA-300 (Australia) atomic absorption spectrometer equipped by hydride generator VGA-76. A mixture of potassium iodide and ascorbic acid was used for pre-reduction of the sample and the extract was acidified by $\mathrm{HCl}$ before measurement.

For cadmium determination a Varian SpectrAA-400 (Australia) atomic absorption spectrometer with GTA-96 graphite tube atomizer was applied. The pyrolytically coated tube with L'vov platform and matrix modifier based on $\mathrm{NH}_{4} \mathrm{H}_{2} \mathrm{PO}_{4}$ solution were used for all the measurements.

For the determination of zinc, the flame atomization (airacetylene flame) was applied (Varian SpectrAA-300 atomic absorption spectrometer). In this case, as well as in the case of cadmium determination, the extracts were acidified by $\mathrm{HNO}_{3}$ before measurement. Analytical results for the three elements are based on standard addition measurement mode in all the cases.

All reagents used were of electronic grade purity (Analytika, Ltd., Czech Republic). 


\section{Results and discussion}

In table II, the relative values of extractable concentrations of elements are compared to the total element content in soils. As expected, the aqua regia was the most efficient extractant and the median recoveries varied in the range of 81-87\% regardless of the element determined. Many authors [13-15] suggested that results of this extracting procedure are similar to them obtained by a total decomposition of the silicate matrix by hydrofluoric acid. In our experiments we encountered some soil samples releasing significantly lower portion of the element (e.g. for one of them $37 \%$ only of the total As). Various recommendations leading to increasing efficiency of aqua regia extraction procedure such as the addition of $\mathrm{H}_{2} \mathrm{O}_{2}$ into the reaction mixture [16] or the use of microwave heating instead of the conventional one [17]. However, the application of an HF-step within the decomposition procedure remains necessary to ensure the total decomposition of the silicate matrix of the sample. The data for element concentrations obtained by the aqua regia extraction can be useful for an approximate knowledge of the total element content in soil. This is especially true if soil samples are affected by anthropogenic contamination where potentially toxic elements have to be evaluated. In such soils we can expect an easier extractability of the contaminant compared to the element bound into the silicate matrix.

The significant differences in extractability of individual elements were obtained in the case of 2 mol. $1^{-1} \mathrm{HNO}_{3}$. For cadmium, no significant difference is observed comparing the aqua regia and nitric acid soluble portions. However, in the case of zinc and arsenic, nitric acid dissolved only 42 and $23 \%$ of the total element content, respectively. Certified reference material RM 7003 Silty Clay Loam was used for quality assurance of the analytical data. For the element portion extractable by cold 2 mol. $1^{-1}$ solution of $\mathrm{HNO}_{3}$, certified values were $1.30 \pm 0.19 \mathrm{mg} \mathrm{As} . \mathrm{kg}^{-1}, 0.23 \pm 0.03 \mathrm{mg}$

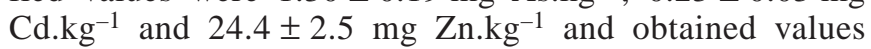
$1.18 \pm 0.07 \mathrm{mg} \quad \mathrm{As}_{\mathrm{kg}} \mathrm{kg}^{-1}, 0.21 \pm 0.03 \mathrm{mg} \quad \mathrm{Cd} . \mathrm{kg}^{-1}$ and

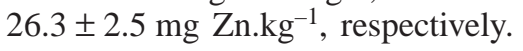

Compared to aqua regia extractable fraction, the variation of the data obtained by the nitric acid extraction procedure was higher among the experimental soils. Evidently, the evaluation of total soil element content based on nitric acid soluble element concentrations [7] is very dangerous and may be acceptable only for the most mobile elements such as cadmium. The increased concentration of the nitric acid up to 4 mol. $\mathrm{l}^{-1}$ followed by a heating of the reaction mixture up to $80^{\circ} \mathrm{C}$ can lead to increased efficiency of zinc extraction up to $80 \%$ [18]. However, for quantitative releasing of the elements from the solid phase of soil to the solution these modifications of the extraction method remain insufficient. Because the method is easy, reproducible, and relatively fast $[1,19]$ and if the differences among the leachability of individual elements are accepted, the 2 mol. $\mathrm{I}^{-1}$ $\mathrm{HNO}_{3}$ extraction may be successfully applied for an approximate evaluation of the soil contamination by potentially toxic elements
Table II. Main statistical characteristics of the data set for relative extractable contents of elements after individual extractions (\% of the total content).

\begin{tabular}{|c|c|c|c|c|}
\hline Arsenic & $\begin{array}{c}0.005 \text { mol. } l^{-1} \\
\text { DTPA }\end{array}$ & $\begin{array}{l}0.43 \text { mol. } l^{-1} \\
\mathrm{CH}_{3} \mathrm{COOH}\end{array}$ & $\begin{array}{c}2 \text { mol. }^{-1} \\
\mathrm{HNO}_{3}\end{array}$ & aqua regia \\
\hline average & 0.139 & 5.70 & 30.1 & 85.6 \\
\hline median & 0.081 & 4.60 & 23.0 & 81.3 \\
\hline stand. deviation & 0.156 & 4.64 & 26.4 & 29.2 \\
\hline minimum & 0.003 & 0.358 & 3.5 & 36.6 \\
\hline maximum & 0.566 & 18.7 & 96.4 & 100 \\
\hline \multicolumn{5}{|l|}{ Cadmium } \\
\hline average & 33.4 & 45.2 & 81.7 & 80.2 \\
\hline median & 30.9 & 43.8 & 93.9 & 87.1 \\
\hline stand. deviation & 15.4 & 18.2 & 29.3 & 23.0 \\
\hline minimum & 6.77 & 11.3 & 19.0 & 29.1 \\
\hline maximum & 83.3 & 82.1 & 100 & 100 \\
\hline \multicolumn{5}{|l|}{ Zinc } \\
\hline average & 4.62 & 9.74 & 48.7 & 79.8 \\
\hline median & 3.59 & 6.93 & 42.0 & 81.0 \\
\hline stand. deviation & 4.00 & 7.89 & 18.7 & 9.62 \\
\hline minimum & 0.558 & 1.28 & 25.4 & 61.0 \\
\hline maximum & 15.2 & 33.4 & 93.9 & 95.3 \\
\hline
\end{tabular}

Diluted acetic acid is characterized as an extractant releasing exchangeable, water and acid soluble (e. g. specifically adsorbed on soil oxides) element fractions [2]. In our case this fraction represents $44 \%$ of the total $\mathrm{Cd}$ and $7 \%$ of $\mathrm{Zn}$ (comparably with previous results [20]), and $4.6 \%$ of As, respectively. The greater variation of values for extractable As and $\mathrm{Zn}$ compared to strong acid procedures suggest that the element extractability by this agent is more related to the complex of physicochemical properties of soils. A similar conclusion may be postulated for the case of $\mathrm{Cd}$ and $\mathrm{Zn}$ extracted by DTPA, creating tight complexes with metal cations bound in surface layer of oxides of $\mathrm{Mn}$ and Fe [3] or by organic bounds [4]. The relative DTPA extractable recoveries of $\mathrm{Cd}$ and $\mathrm{Zn}$ were about $25 \%$ lower than with using acetic acid but the distribution of data was comparable. The agreement between the present results and those of our previous study [20] was fairly good. The extractability of arsenic did not exceed $1 \%$ of total content. Arsenic is present in soil mostly in anions and the extractant developed for release of cationic forms of elements is not useful in this case.

The detailed evaluation of the $\mathrm{As}, \mathrm{Cd}$ and $\mathrm{Zn}$ distribution into individual soil fractions according to the modified SM\&T EUR 14763 EN [5] sequential extraction scheme was published previously [21]. In this paper we compared the efficiency of single extraction procedures with element portions present in water soluble, exchangeable, bound on oxides, organically bound, and residual fractions. The bars in figure 1 represent the medians of relative element contents released by individual extraction agents regarding to the medians of relative element contents in soil fractions except the residual one. To fulfill the comparison, the previously 

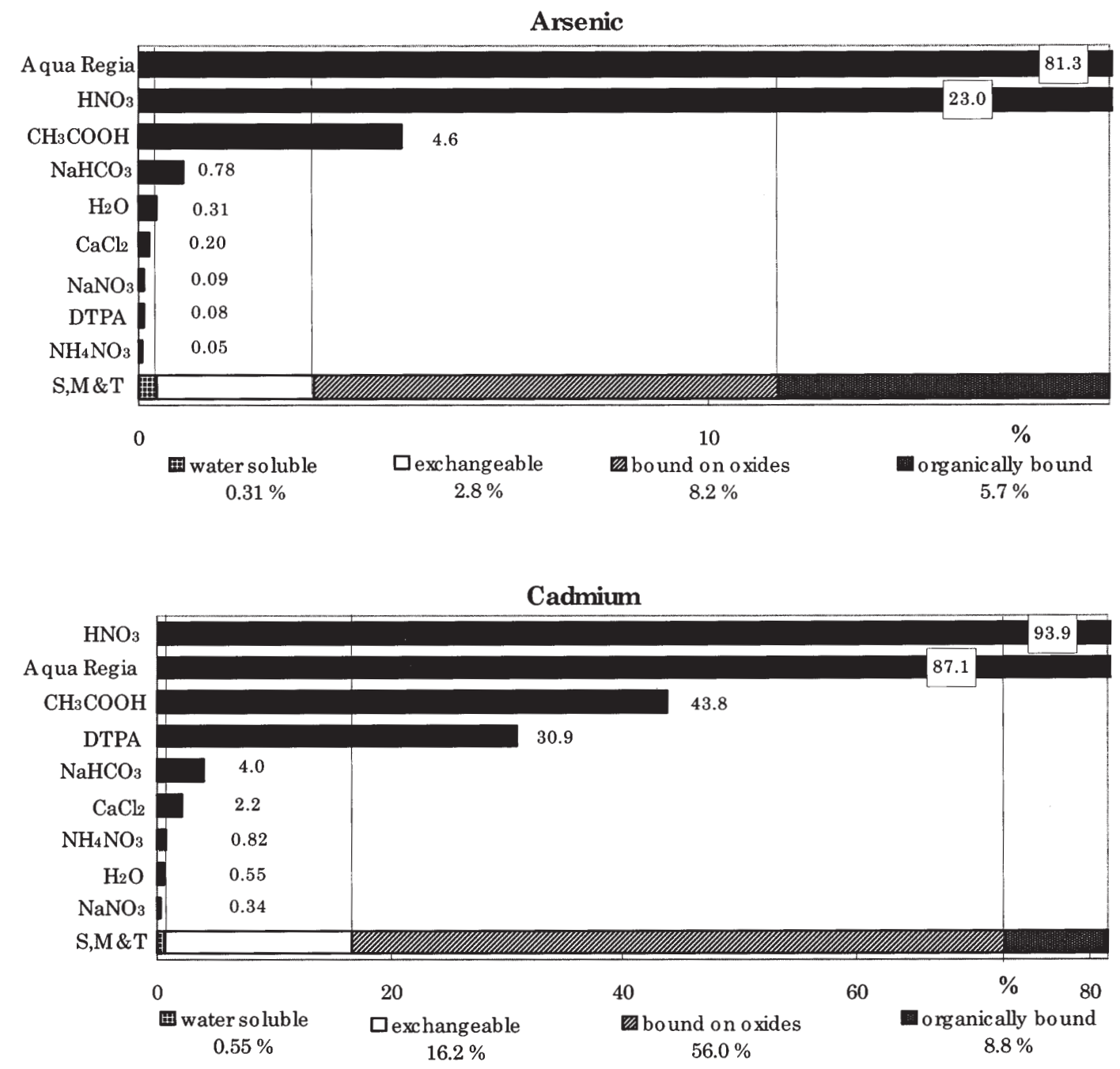

Zinc

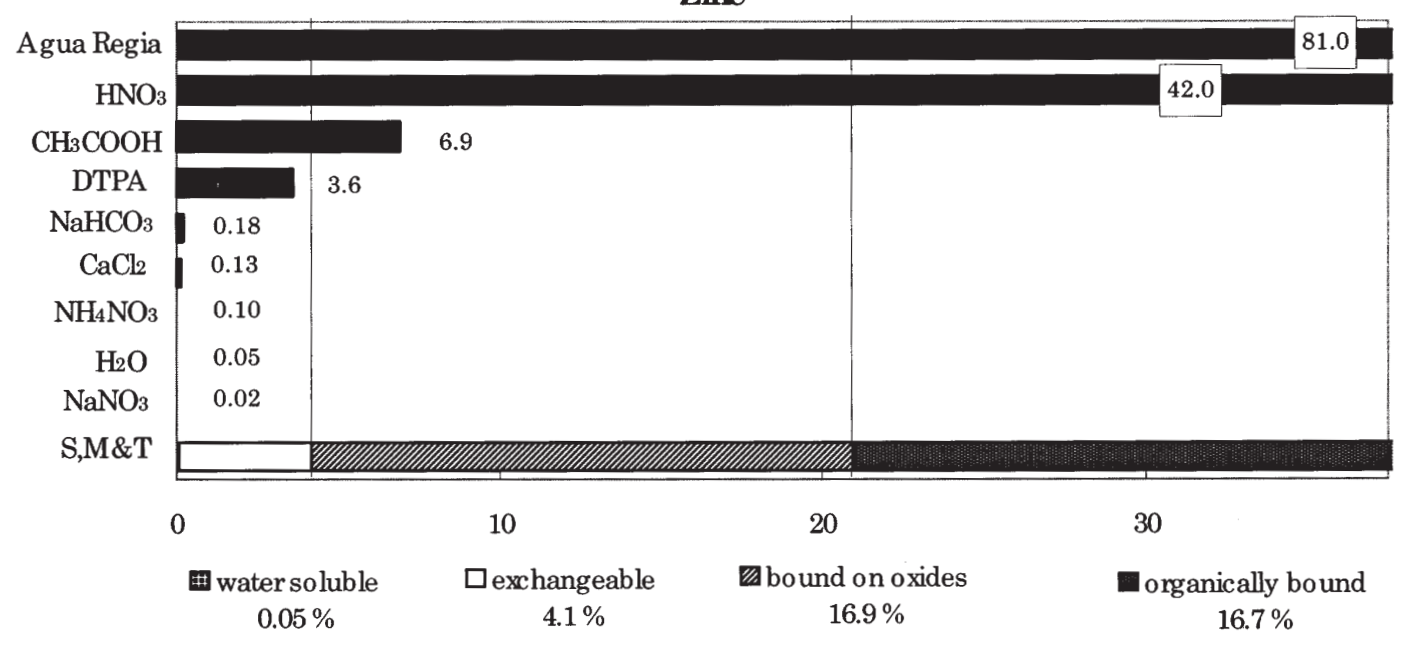

Figure 1. Medians of extractable concentrations of $\mathrm{As}, \mathrm{Cd}$ and $\mathrm{Zn}$ according to individual extractants as compared to the distribution of elements to individual soil fractions after SM\&T sequential extraction scheme (\% of the total content). 


\section{Original articles}

evaluated [10] element contents extractable by mild soil extractants, i.e. salt solutions and water, are also indicated.

Evidently, aqua regia is the only agent releasing the most significant portion of residual element fraction, i.e. the portion bound in the silicate matrix of the soil sample. Approximately, nitric acid is able to dissolve the element portion comparable to the sum of labile soil element fractions. The regression analysis indicated an increasing extractability of soil elements by nitric acid if the residual element fraction decreases, as well $\left(r_{\mathrm{As}}=0.3, r_{\mathrm{Cd}}=0.4\right.$, $r_{\mathrm{Zn}}=0.6$ ). Acetic acid can partially release the element portion bound on oxides accordingly to literature sources [2] and recoveries exceeded the sum of water soluble and exchangeable fraction for all the three elements. Apparently, this agent was not able to dissolve quantitatively the element fraction bound on oxides. In this case, the detailed resolution of individual types of soil oxides of $\mathrm{Mn}$ and $\mathrm{Fe}$ within the sequential extraction scheme can be helpful as described in literature [22]. Also DTPA has shown to be the extractant which attacks both oxide and organic fractions of $\mathrm{Cd}$, as mentioned above, while $\mathrm{Zn}$ concentrations in DTPA extracts did not exceed the sum of water soluble and exchangeable fraction.

The sequential analytical procedure applied in this experiment is a compromise performed to unify and considerably simplify methods used within the European Union. For this reason, the obtained information concerning the element fractionation by this method is limited and insufficient for a detailed study of behavior of element bounds in soil. This is evident especially for the fraction called as "exchangeable" which includes also the element fraction bound on carbonates. As may be shown in figure 1, the extractants based on salt solutions and/or water were able to release only small portion of elements leachable within the "exchangeable" fraction. No relationships were found by regression analysis between $\mathrm{Cd}$ and $\mathrm{Zn}$ contents extractable by neutral salt solutions and the exchangeable fraction of these elements. The leachability of $\mathrm{Cd}$ and $\mathrm{Zn}$ by the neutral salt solutions is predominantly affected by the soil reaction. If a 0.11 mol. $\mathrm{l}^{-1}$ solution of acetic acid is applied for the extraction of their "exchangeable" fraction, the differences in soil $\mathrm{pH}$ are hidden by high acidity of the extracting agent. For arsenic, the significant correlation was found for the single mild extractants as related to As present in the individual fractions $(r=0.51-0.55)$. The extractability of arsenic is probably affected by the complex of physicochemical soil properties by the similar way if the single soil extraction procedures [10] or the sequential extraction scheme [21] are used.

The concentrations of As, $\mathrm{Cd}$, and $\mathrm{Zn}$ determined in soil extracts by both mineral and organic acids covered in most cases the element portion representing more than one soil element fraction determined using SM\&T sequential extraction procedure. The more detailed resolution of the easily soluble element fractions $[3,8,22]$ can lead to better under- standing of the dynamics of changes in element distribution in individual soil fractions as well as the plant-availability of the elements.

\section{Acknowledgments}

Financial support for these investigations was provided by Czech Ministry of Education Project No. CEZ:JO3/985 and by the internal project of Czech University of Agriculture No. 204/10/25098/0.

\section{References}

1. Beneš, S. Obsahy a bilance prvků ve sférách životního prostředí. Part I., Prague: Ministry of Agriculture, 1993, p. 73.

2. Miller, W. P.; Martens, D. C.; Zelazny, L. W.; Kornegay, E. T. J. Environ. Qual. 1986, 15, 69.

3. Miller, W. P.; McFee, W. W. J. Environ. Qual. 1983, 12, 29.

4. Hickey, M. G.; Kittrick, J. A. J. Environ. Qual. 1984, 13, 372.

5. Ure, A.; Quevauviller, P.; Muntau, H.; Griepink, B. BCR information EUR 14763 EN, Community Bureau of Science, 1993.

6. Oake, R. J.; Booker, C. S.; Davis, R. D. Wat. Sci. Tech. 1984, 17, 587.

7. Borůvka, L. Doctoral thesis, University of Agriculture, Prague, 1997.

8. Tessier, A.; Campbell, P. G. C.; Bisson, M. Anal. Chem. 1979, 51,844 .

9. Quevauviller, P.; Ure, A.; Muntau, H.; Griepink, B. Intern. J. Environ. Anal. Chem. 1993, 51, 129.

10. Száková, J.; Tlustoš, P.; Balík J.; Pavlíková, D.; Balíková, M. Chem. Listy, in press.

11. ISO, International Standard Organization Soil quality extraction of trace metals soluble in aqua regia, ISO standard of ISO/TC 190/SC 3/ WG.

12. Száková, J.; Tlustoš, P.; Pavlíková D.; Balík, J. Chem. Listy 1997, 91, 580.

13. Agricultural Research Center, Department of Soil Science Methods of soil and plant analysis; Jokioinen: Finland, 1986.

14. Baghdady, N. H.; Sippola, J. Acta Agric. Scand. 1984a, 34, 339.

15. Baghdady, N. H.; Sippola, J. Acta Agric. Scand. 1984b, 34, 345.

16. Žemberyová, M.; Smirnová, L.; Vačková, M. Agrochémia 1991, 31, 282.

17. Nienwenhuize, J; Poley-Vos, C. H; Van Den Akker, A. H.; Van Delft, W. Analyst 1991, 116, 347.

18. Cao, H.; Chang, A. C.; Page, A. L. J. Environ. Qual. 1984, 13, 632.

19. Němeček, J.; Podlešáková, E.; Pastuszková, M. Rostl. Výr. 1995, 41, 25.

20. Tlustoš, P.; van Dijk, D.; Száková, J.; Pavlíková, D. Rostl. Výr. 1994, 40, 1107.

21. Száková, J.; Tlustoš, P.; Balík J.; Pavlíková, D.; Vaněk, V. Fresenius J. Anal. Chem. 1999, 363, 594.

22. Zeien, H.; Brümmer, G. W. Mitteilungen Dt. Bodenkundl. Gesselsch. 1991, 66, 439. 